\title{
Exchange Rate Volatility and Tourist Flows into Turkey
}

George Agiomirgianakis

Hellenic Open University, Patras, Greece

Dimitris Serenis

University of Wolverhampton, Wolverhampton, United Kingdom

Nicholas Tsounis

Technological Institute (TEI) of Western Macedonia, Kastoria, Greece

Hellenic Open Universtiy, Patras, Greece

\begin{abstract}
This paper examines the effects of Exchange Rate Volatility on tourist flows into Turkey for the period of 1994 2012. Our results show that (i) there is a negative relationship between exchange rate volatility and tourist inflows into Turkey; (ii) there is a negative impact of the relative price ratio on the tourist flows indicating that relatively expensive places deter tourist arrivals, given the keen international competition among alternative destinations; (iii) GDP per capita at tourist origin, measured in Purchasing Power Parities, exerts positive influence on tourist flows. Our findings thus, suggest some direct policy implications: first, policy makers of a tourist destination country aiming to target potential markets for their tourist products, should, in principle, avoid markets prone to exchange rate volatility due to political and social upheavals or financial instability.
\end{abstract}

\footnotetext{
* Corresponding Author: George Agiomirgianakis; Business Administration Programme, School of Social Sciences, Hellenic Open University, Bouboulinas 57-59 Patras 26222, Greece; Greek; Tel: +30 2610267451, Fax: +30 2610367442, E-mail: mailto:gmagios@otenet.gr.

Co-Author: Dimitrios Serenis; Department of Business Solutions, University of Wolverhampton, Wulfruna St, Wolverhampton, West Midlands, WV1 1LY, United Kingdom; Greek; Tel: +44 7773201126, E-mail: dseren01@ yahoo.com;

Nicholas Tsounis; Department of International Trade, TEI of Western Macedonia, Fourka Area, 52100, Kastoria, Greece; Greek; Tel: +30 2467087197, Fax: +30 2467087063, E-mail: mailto:tsounis@kastoria.teiwm.gr.
} 
Moreover, countries relying heavily on their tourism industry, should avoid using exchange rate policies for other policy objectives like international price competiveness, as these policies may end up to an exchange rate volatility that could reduce its tourism inflows substantially in the longer run.

JEL classifications: F41, L83

Keywords: Exchange Rate Volatility, Tourist Flows, Turkey, ARDL Method

\section{Introduction}

International tourist flows have increased sharply in the last six decades, becoming one of the largest and fastest growing sectors worldwide. Indeed, tourist arrivals started from 25 million in 1950, reached 278 million in 1980, 528 million in 1995, and 1,087 million in 2013. In 2013, the growth rate of tourist arrivals was 5\% (UNWTO 2014). Moreover, this increase in tourist arrival is expected to last, by an average, long term growth of $3.3 \%$ a year, i.e., average of 43 million a year, reaching 1.8 billion by 2030 (UNWTO 2011). These future increases in tourist arrivals will benefit emerging economies, having a $57 \%$ share, compared to the $43 \%$ share in the tourist arrivals of advanced economies destinations. Furthermore, certain regions of the world such as Europe, Asia, and the Pacific will gain most of the new arrivals while lower increases will be incurred by Americas, Middle East and Africa. In terms, of growth rates, however, Asia and the Pacific region is expected to have the highest growth rates of $4.9 \%$ out of all world regions.

In addition to these large and increasing tourist flows, UNWTO reports that in 2013, the growth in the revenues accrued by destination countries equals the growth in international arrivals, 5\%, which in absolute terms was 1.159 billion US dollars. ${ }^{1}$ If, however, we add the earnings from the receipts of international passenger transport services rendered to non-residents, the total contribution of tourism amounts to 1.4 trillion US dollars (UNWTO 2014, p. 6).

Thus, international tourist flows and their associated financial flows are huge and

\footnotetext{
'According to UNWTO (2014), "International tourism receipts are the earnings generated in destination countries from expenditure on accommodation, food and drink, local transport, entertainment, shopping and other services and goods."
} 
increasing overtime, signifying an increasing role of the tourist sector worldwide and justifying the reasons why governments and internationals institutions such as the International Monetary Fund (IMF) and World Bank alike, suggest that the tourist sector is a driver of economic growth and a tool for fighting recession and its symptoms such as high unemployment rates incurred in several countries. ${ }^{2}$

On the other hand, competition among destinations countries in attracting tourists is keen and depends on a number of reasons among which prominent role is attributed to economic, political and social stability at the destination country. Stability, either economic, political or social in a country, is often, realized by tourists in terms of an exchange rate stability which, in turn, is attributed to the economic policies followed by policymakers at a tourist destination country. For example, conflicting or disturbing economic policies in a destination country will be reflected in an exchange rate volatility which, given the keen international competition among tourist destinations, will result in a volatile number of tourist arrivals and tourist revenues for that country. Therefore, volatility at a tourist destination country raises the issue of economic policies pursued at a destination country and their effect on tourism sector.

Empirical studies have shown that changes in the exchange rates are associated with changes in international arrivals: devaluation at a destination country induces inflows while devaluation at the origin country deter international tourist outflows. Although many studies were conducted on the role of the exchange rate, either as a direct determinant or an indirect one, via its impact on relative prices between origin and destination, less attention has been given to the Exchange Rate Volatility (ERV) that by creating an environment of uncertainty with incurring volatile exchange rates may reduce tourist inflows. This is the case not only through individual tourists changing their holiday plans, but also tour operators perceiving ERV as an element of risk for their profits and may thus react by redirecting tourist flows into other competitive destinations that enjoy relative stable exchange rates. The purpose of this paper is to explore the relationship between tourism flows and exchange rate volatility for Turkey, a country that is known to be a major European destination for summer holidays.

The structure of the paper is as follows. Section II provides an overview of the relevant literature. Section III justifies the choice of the specific model and the variables. In Section IV, data description and methodology issues are analysed. Section V presents our results and finally Section VI concludes along with some policy implications derived

\footnotetext{
${ }^{2}$ See Agiomirgianakis et al. (2014a and 2014b) for an analysis of tourism demand in Greece.
} 
from our findings.

\section{Literature Review}

Four major determinants of international tourist flows are identified by the relevant literature: (i) the Real Effective Exchange Rate (REER); (ii) the relative prices between destination and origin; (iii) the income, approximated by the GDP of the origin country and (iv) the transportation cost (Cheng Ka Ming 2012, Dwyer et al. 2011, Zhang et al. 2009, Song and Li 2008, Zaki 2008, Patsouratis et al. 2005, Li 2005, Garin-Munoz 2000, Witt and Witt 1995, Crouch 1993).

These empirical studies have concluded that an exchange rate devaluation at the destination attracts tourist inflows while an exchange rate revaluation at the origin reduces tourism outflows. According to Agiomirgianakis 2014, Song and Li 2008, Garin-Munoz 2000, Patsouratis et al. 2005, and Witt and Witt 1995 adopting what Artus 1970 has suggested, namely, that travelers are more aware of exchange rates that they use and use them as the proxy for the cost of living abroad (Stabler et al. 2010, p. 53 55). An increase in imcome in the country of origin positively affects the ability of people for travelling abroad. The cost of living at a destination relative to an origin, given by relative consumer prices between destination and origin is negatively related to tourism inflows (Dwyer et al. 2010, p. 63 64). Transportation costs which is part of the overall cost of travelling to a destination, is negatively related to tourist flows.

In examining the literature on the effects of exchange rates on international tourist flows, one may note that much emphasis has been given to the changes, shocks or fluctuations in the exchange rate. Several studies have shed some light in this area. Patsouratis (2005) shows that exchange rate fluctuations may be identified as the sole factor determining tourist flows, as in the case of German tourist inflows in Greece. ${ }^{3}$

Earlier studies on the effects of exchange rate fluctuations on international tourist flows are summarized by Crouch (1993). Fewer studies focus on the ERV such as Webber (2001), Chang et al. (2009), Yap (2012), and Santana Gallego (2010). In a seminal paper by Webber (2001), ERV is identified as a significant determinant of the

${ }^{3}$ See the discussion below on Webber (2001). 
long run demand for tourism, as risk averse tourist may decide to cancel, delay or even switch to another tourist destination if there is too much volatility of the exchange rate at the destination of their initial choice. Moreover, ERV may reflect political instability or social unrest in the destination country, deterring tourists from this destination. Webber (2001) examined tourist outflows from Australia and showed that ERV may lead tourists to abandon the idea of travelling to a particular country in $40 \%$ of cases.

Chiang et al. (2009) initiated a further analysis into the effects of ERV, showing that it is indeed associated with international tourist inflows in Taiwan. Yap (2012), initiated by the findings of Chiang et al. (2009), investigated whether ERV results in an increase in the uncertainty of tourist inflows into Australia, concludes that exchange rate volatility create spillover effects on tourism inflows into Australia although these effects may differ from stronger to weaker, depending upon the origin country. On the other hand, Santana Gallego (2010) concludes that ERV of zero i.e., a common currency, has the largest impact on tourism, claiming that Euro has increased tourist flows by $6.3 \%$. Furthermore, Thompson and Thompson (2010) found a positive euro effect due to zero ERV for Greece. Finally, the literature identifies mixed effects of volatility on exports (not tourist exports) across countries and sectors (Fang et al. 2007, Serenis, D. and Tsounis, N. 2014).

According to Webber (2001), the effects of ERV on tourist arrivals depend on whether tourists are risk-averse or risk-lovers. ERV has a negative impact on the decision to travel for risk-averse tourists and therefore, cause lower arrivals while, it has a positive impact to risk-seeking tourists because it is seen as a chance for making some profits and therefore, leads to higher arrivals. Overall, however, it is expected that the number of risk-averse tourists will be significantly larger than the risk-lovers; moreover, since tourist arrivals are dominated by package tourism, tour operators will switch locations to avoid ERV. ${ }^{4}$ Finally, ERV is identified in the above literature as a long run influential factor on tourism demand which is the case for our study given that we examine tourist flows into Turkey for eighteen years using quarterly data.

Further, the literature identifies that income elasticity is an important determinant for tourist arrivals: the higher the income at home, the more domestic people travel abroad. Tourism is expected to have income elasticity with values greater than one, i.e., tourism is a luxury good. In Lee et al. (1996), income elasticities for tourist arrivals in

\footnotetext{
${ }^{4}$ Tour operators may hedge their activities away from countries incurring ERV, see, e.g. Stabler et al. (2010 p.176 181) for a relative analysis.
} 
different countries were found to be within the range of 0.333 to 14.3. Witt and Martin (1987) has calculated income elasticity to be 6.35 for Greece and Tremblay (1989) and 11.35 for Portugal. The value of income elasticity depends on (i) the level of economic development of the tourists' home countries. Developed countries score higher than one for the income elasticity while developing countries have less than one; (ii) the cyclical pattern of a country's economic growth; (iii) the form of travel where independent travel has lower values of income elasticity while package tour has higher values of income elasticity. In our study, high values of income elasticity are expected to be found because about $80 \%$ of tourists going to Turkey come from Western European countries and tourism in Turkey is dominated by package tours. Also, most of the years included for the analysis do not include recession years.

\section{The Model}

The model for examining the effects of ERV on tourist flows is used also by Serenis and Tsounis (2014a and 2014b) to examine the effects of ERV on total and sectoral exports. Here, it is modified to examine the effects of ERV on tourist arrivals, to include different volatility measures and also to account for seasonality effects. Tourist flows, measured by tourist arrivals, are considered to be a function of relative prices, weighted GDP per capita of the tourists' home countries, the weights being the share of the number of tourist arrivals from one country out of the total number of tourist arrivals in the destination country and exchange rate volatility, as follows:

$$
X_{t}=f\left(P_{t}, G D P_{t}, V_{t}\right)
$$

where $X$ is the number of tourist arrivals, $P$ is calculated as $P_{X} / P_{w}$, i.e., the relative Consumer Price Index (CPI) between domestic country and the Rest Of the World (ROW), GDP is GDP per capita of the origin countries of tourists, measured in Purchasing Power Parities (PPPs) and weighted by the number of tourist arrivals from the origin country into the total number of tourist arrivals in Turkey and $V$ represents the two different measures of volatility. In the econometric specification of the model, three 
seasonal dummies D1, D3, D4 and a time trend, $T$, were included. ${ }^{5}$

The number of tourist arrivals is the number of persons (residents and non residents) arriving with the sole purpose of tourism. The relative prices variable is constructed from the country's CPI deflated by an index comprised of world CPI for each country in our sample. ${ }^{6}$ The variable following the relative prices is GDP per capita of the origin countries, measured in PPPs. The variable is calculated as a weighted average of the GDP per capita of the tourists' origin country, the weights being the share of specific country in the total number of tourist arrivals in Turkey. It has been included in the model because vacations are affected by income.

Finally, the last variable, $V$, represents exchange rate volatility which is measured in two ways: (i) as a measure of time varying exchange rate volatility, using the standard deviation of the moving average of the logarithm of real effective exchange rate and (ii) as a measure of high and low fluctuation of the average values of volatility by utilizing a variable that captures high and low peak values of the REER.

\section{A. Exchange rate volatility measurement}

ERV is a measure that is not directly observable thus, there is no right or wrong measure of volatility. Even though some empirical researchers have examined alternative measures of volatility, for the most part, the literature utilizes a moving average measure of the logarithm of the exchange rate,

$$
V_{t+m}=\left[\frac{1}{m} \sum_{i=1}^{m}\left(R_{t+i-1}-R_{t+i-2}\right)^{2}\right]^{\frac{1}{2}}
$$

where $R$ is the logarithm of the nominal or real effective exchange rate, $m$ is the number of periods, usually ranging between $4 \sim 12$.

The application of such measure has its benefits and pitfalls. The main disadvantage is that it fails to capture and incorporate the potential effects of high and low peak values of the exchange rate.

High and low peak values of the exchange rate capture the unpredictable factor which

\footnotetext{
${ }^{5}$ The full econometric specification of the estimated model is given in Equation (3) below.

${ }^{6}$ The inclusion of the relative consumer price $P_{X} / P_{w}$ approximates the cost of tourism as it is adjusted by the exchange rate. For this reason, we do not include exchange rate as a separate variable. See Witt and Witt (1995) and Patsouratis (2005) for a more detailed analysis.
} 
may alter the tour operators' behaviour. Many empirical researchers have commented on the importance of unexpected values of exchange rate for exports. Akahtar and Hilton (1984) concluded that the exchange rate uncertainty is detrimental to the international trade. Other researchers have applied volatility measures which attempted to incorporate unexpected movements of the exchange rate. Some have proposed the average absolute difference between the previous forward rate and the current spot rate as a better indicator of exchange rate volatility (Peree and Steinherr 1989). Awokuse and Yuan (2006) applied a measure of volatility which included the variance of the spot exchange rate around the preferred trend. However, as suggested by De Grauwe (1988), risk preferences to unpredictable movements of the exchange rate play a vital role on exporters' behaviour. As a result, it is possible for a producer to either increase or decrease exports during a period for which exchange rates take extremely high and low values. A moving average does reduce these high and low values and therefore, in some cases of extreme fluctuations of the exchange rate proves inadequate to fully capture the effects of volatility on exports.

Keeping in mind of the above arguments, we examine two sets of estimated equations. The first contains the standard deviation of the moving average of the logarithm of REER as a measure of volatility $(V 1)$ and the second contains a variable capturing only high and low values of $\operatorname{REER}(V 2)$.

In order to derive the second measure of volatility, the average value of REER is calculated. $V 2$ is constructed to capture only the values for which the exchange rate fluctuates above and below a certain percentage of the average value. Since we do not know which values are perceived as high or low points for each country, we examine various cases for which the exchange rate increases above and below certain thresholds ranging from $3 \sim 7 \%$ and report the first statistically significant values that we obtain.

\section{B. Data description and methodology}

Quarterly data for Turkey are employed to explore the relationship between tourism services exports and exchange rate volatility that cover the period of the fourth quarter of 1994 to the fourth quarter of 2012. Tourist arrivals were obtained from Turkey's statistical office, GDP was obtained from Eurostat while the CPI values and Real Effective Exchange Rates (REER) are derived from International Financial Statistics (IFS). 


\section{Estimating methodology}

Cointegration analysis has been used in order to examine the long-run relationship between the tourist flows, the ERV and the other explanatory variables of GDP per capita and relative prices. Cointegration analysis is used to test for the existence of a statistically significant connection between two or more time series by testing for the existence of a cointegrated combination of the two series. If such a combination has a low order of integration, this can signify an equilibrium relationship between the original series, which are said to be cointegrated. Cointegration analysis is necessary rather than common linear regression methods because if the latter are used on non-stationary time series, it will produce spurious results.

Before examining the existence of cointegration between the variables, we first analyse the order of integration of the variables considered. This analysis is necessary in order to choose the right method for testing for cointegration among the chosen variables. When there are only I(1) variables in a model, the maximum likelihood approach of Johansen and Juselius (1990) can be used. However, if the system contains both I(0) and I(1) variables, then this method cannot be used because it may produce spurious results. Instead, the Autoregressive Distributed Lag (ARDL) method can be applied on a time series data, irrespective of whether the variables are I(0) or I(1) (Pesaran and Pesaran 1997).

Therefore, in order to choose the right method for conducting the cointegration analysis, it is first necessary to establish the order of integration of the variables. This is done by using the ADF (Dickey and Fuller 1981) or the P-P (Phillips and Perron 1988) unit root test. Here the P-P unit root test was used to test the series for stationarity.

${ }^{7} \mathrm{I}(\mathrm{d})$ denotes the order of the integration of a time series, i.e., it shows the minimum number of differences required to obtain a covariance stationary series. 
Table 1. Phillips-Peron unit root test results

\begin{tabular}{|c|c|c|}
\hline Series & Level & $\begin{array}{c}\text { First } \\
\text { difference }\end{array}$ \\
\hline $\ln X$ & -2.02204 & $-4.85082^{*}$ \\
\hline $\ln G D P$ & $-7.10305^{*}$ & $-4.35388^{*}$ \\
\hline$V 1$ & -3.665791 & $-6.15042^{*}$ \\
\hline $\ln P$ & -2.484047 & $-5.67965^{*}$ \\
\hline$V 2$ & $-4.59118^{*}$ & $-6.55632^{*}$ \\
\hline
\end{tabular}

(Notes) All tests are performed using the $5 \%$ level of significance; $\ln \mathrm{X}$ is the logarithm of tourist arrivals, In GDP represents the logarithm of a weighted index composed of the sums of each countries' real GDP per capita in PPP multiplied by the corresponding percentage of tourist flows from each country to Turkey, $V 1$ is volatility measured as the moving average of the standard deviation of REER, $V 2$ is the volatility measured capturing values above and below $6 \%$ of the average value of the moving average of REER and $\ln P$ is the logarithm of the country's CPI to world's CPI. All tests are performed to a maximum of three lags. The null hypothesis of a unit root is tested against the alternative. * denotes significance at least at 5\% level.

(Source) Authors' calculations.

The values of the P-P test are presented in Table 1. The null hypothesis $\left(\mathrm{H}_{0}\right)$ of a unit root (non-stationarity) is tested against the alternative. $\mathrm{H}_{0}$ was rejected at $5 \%$ level of statistical significance for $\ln G D P$ and $V 2$ while $\ln X, V 1$ and $\ln P$ were found to be non-stationary at their level. However, the null hypothesis was rejected for their first difference and it is concluded that the variables $\ln G D P$ and $V 2$ are $\mathrm{I}(0)$ while $\ln X, V 1$, and $\ln P$ are $\mathrm{I}(1)$.

In our case, the system contains both $\mathrm{I}(0)$ and $\mathrm{I}(1)$ variables and therefore, the ARDL modeling suggested by Pesaran et al. $(1999,2001)$ will be used. It provides unbiased estimates of the long-run model and validates the $t$-statistics even when some of the regressors are endogenous (Laurenceson and Chai 2003). However, it is necessary to check that the variables are not I(2) because, in this case, ARDL would produce spurious results (Oteng-Abayie et al. 2006). As it can be seen from Table 1, the variables are either stationary on their level or at their first difference.

Following Perasan et al. (1999, 2001), the ARDL representation of Equation (1) is 


$$
\begin{aligned}
\Delta \ln X_{t}=a_{0}+\vartheta & \ln X_{t-1}+\sum_{i=1}^{\mu} \theta_{i} G_{i, t-1}+\sum_{j=1}^{p} a_{j} \Delta \ln X_{t-j} \\
& +\sum_{i=1}^{\mu} \sum_{j=0}^{p} \beta_{i j} \Delta G_{i, t-j}+\tau T+\delta_{1} D 1+\delta_{3} D 3+\delta_{4} D 4+\omega_{t}
\end{aligned}
$$

where $\Delta$ is the first-difference operator, $X$ is the exports of tourist services, $G=(\ln P$, $\ln G D P, V 1$ or $V 2)$ is the vector with the explanatory variables; $P$ is the relative prices, $G D P$ variable is the weighted real domestic GDP per capita where the weights used are the shares of the tourist flows from each country out of the total Turkey's tourist arrivals, $V 1$ and $V 2$ represents the first and second measure of ERV, D1, D3, D4 are seasonal dummies, $T$ is the time trend, $\omega$ is a white noise error term, $\mu=3$ is the number of explanatory variable, $\vartheta, \theta_{i}$ are the coefficients that represent the long-run relationship, $\alpha_{j}, \beta_{i j}$ are the coefficients that represent the short-run dynamics of the model and $p$ is the number of lag length and, for Equation (3), it is equal to 7. The ARDL method to cointegration requires: first, Equation (3) is estimated and the lag order of the ARDL is determined using the AIC (Akaike Information Criterion) ${ }^{8}$ lag selection criterion. For the determination of the lag order of the ARDL model, the maximum number of eight lags in Equation (3) was considered and therefore, $7 \times 8^{\mu}=3584$ regressions were estimated $^{9}$ for each measure of volatility.

Second, a test was conducted that the errors in Equation (3) are serially independent. This test examines whether or not the residuals are autocorrelated. If the latter is detected by an appropriate test, then the standard errors of the estimated coefficients tend to be underestimated and therefore, their statistical significance which is indicated by the $t$-statistic is overestimated. The Lagrange Multiplier (LM) test was used to test the null hypothesis that the errors in Equation (3) are serially independent against the alternative that there are autoregressive or moving average relationships in the errors.

Then, the model is tested for dynamic stability. If a model has Auto Regressive (AR) terms, then the estimated coefficients from the lagged terms of the dependent variable have to be tested in order to see whether the model is stationary or not. The model in Equation (3) has AR terms presented by the second summation term.

Fourth, from Equation (3), a test for the existence of long-run relationship was

\footnotetext{
${ }^{8}$ Akaike Information Criterion is a measure of the relative quality of a statistical model for a given set of data and therefore, it provides a means for model selection.

${ }^{9}$ It is $7 \times 8^{\mu}$ because as it can be seen from Equation (3), the second summation term runs from 1 to 7 while the other three $(i=1, \ldots, 3)$ run from 0 to 7 .
} 
conducted. This is called the bounds testing approach to cointegration and it is associated to the hypothesis testing $\mathrm{H}_{0}: \vartheta=\theta_{1}=\cdots=\theta_{i}=0$; i.e., the long-run relationship does not exist whereas the alternative hypothesis $H_{1}: \vartheta \neq \theta_{1} \neq \cdots \neq \theta_{i} \neq 0$ assumes that the long-run relationship exists. Testing the null hypothesis against the alternative is done using the $F$-statistic from the Wald test. ${ }^{10}$ If the computed $F$-statistic falls outside the critical value bounds, a conclusive inference can be made about the cointegration of the series in the model. If however, the $F$-statistic falls inside the critical values' band, then no conclusive inference about the cointegration (long-run relationship) of the series can be made.

Fifth, assuming that the bound test is conclusive and there is a cointegrating relationship, the coefficient of the Error Correction Term (ECT) and its statistical significance can be found by estimating:

$$
\Delta \ln X_{t}=a_{0}+\sum_{j=1}^{p} a_{j} \Delta \ln X_{t-j}+\sum_{i=1}^{\mu} \sum_{j=0}^{p} \beta_{i j} \Delta G_{i, t-j}+e E C T_{t-1}+\omega_{t}
$$

The coefficient of the error correction term, $e$, should be negative and statistically significant, meaning that there is a cointegration between the dependent and the explanatory variables. The value of this coefficient shows the percentage change of any disequilibrium between the dependent and the explanatory variables that is corrected within one period (one quarter).

Finally, the long-run impact of the explanatory variables to the dependent variable is calculated using the expression (Bardsen 1989):

$$
\hat{\gamma}_{i}=-\frac{\hat{\theta}_{i}}{\widehat{\vartheta}}
$$

where $\hat{\theta}_{i}$ and $\hat{\vartheta}$ are the estimated long-run coefficients in Equation (3). The $\hat{\gamma}_{i}$ s show how the dependent variable, the logarithm of tourist flows, measured by tourist arrivals, responds in the long-run to any change in the explanatory variables i.e., the logarithm of the GDP per capita, the logarithm of the relative prices, and the logarithm of the measure of ERV. However, the $\hat{\gamma}_{i}$ s provide a single value to quantify the long-run effect and

\footnotetext{
${ }^{10}$ The Wald test is used to test the true value of coefficient(s) based on the sample estimate. In this case, it is used to test whether or not the coefficients that show the long-run relationship among the variables (i.e., the $\vartheta$ and $\theta_{i}$ s of Equation 3 ) are equal to zero. If they are, then there is no long-run relationship (cointegration) among them. The Wald test is used for the calculation of the $F$-statistic. Then the bounds test, suggested by Pesaran et al. (1999, 2001), is used to conduct the hypothesis testing.
} 
they do not provide any information about the degree of variability associated to them (Gonzalez-Gomez et al. 2011). Further, confidence intervals for each coefficient cannot be constructed using traditional statistical inference because they do not follow the normal distribution since they are calculated as the division of two normally distributed variables. Following Efron and Tibshirani (1998), the bootstrap method, which is a nonparametric method, can be used in order to calculate confidence intervals empirically without assuming a specific distribution of the $\gamma_{i}$ s. In our case, this was made for $95 \%$ level of statistical significance. If the zero is contained in the interval, then the effect of the explanatory variable will not be statistically significant.

\section{Results}

The lag order of the ARDL model, found with the procedure described in the section above, is: $(7,6,0,2)$, for both measures of volatility. The first number represents the distributed lags of $\ln X$, the second represents the distributed lags of $\ln P$, the third represents the distributed lags of $\ln G D P$ and the fourth represents the distributed lags of $V 1$ or $V 2$. The regression results and the necessary diagnostic statistics for the ARDL models are presented in the Appendix. The long-run impact of ERV on tourist flows is shown in Table 3 and it will be further discussed below.

The Lagrange Multiplier (LM) test was used to test the null hypothesis that the errors in Equation (3) are serially independent. ${ }^{11}$ The $F$-statistic of the LM test had a value of 1.109 using measure 1 and 0.535 using measure 2. Therefore, it was not significant and so, the null hypothesis of no-serial correlation was not rejected.

A further test was conducted to detect the presence of heteroskedasticity in both models. If there is presence of heteroskedasticity, the variance of the regression residuals will not be constant, causing the standard errors of the coefficients to be biased. The biased standard errors lead to biased inference, so the results of the hypothesis tests may be possibly wrong. Therefore, it was necessary to exclude the presence of heteroskedasticity in both models. The Breusch-Pagan-Godfrey heteroskedasticity test was performed to detect the presence of heteroskedasticity and it is reported in the Appendix; the $F$-statistic of this test had a value of 0.736037 for measure 1 and 1.447288 for measure 2. It was not statistically significant in both models, signifying that the null hypothesis of homoschedasticity has failed to be rejected.

A further test was performed to examine the structural stability of the coefficients

\footnotetext{
${ }^{11}$ Please see the previous section for a description of this test.
} 
of the two models. This is necessary because the time series is long that includes observations from 73 time periods and the value of the coefficients of the variables in both models may have been changed over time. If a change in the coefficient is made over time, it is called a structural break. The Chow test is used to test for the presence of a structural break in the coefficients for the middle of the sample period, i.e., the 36th observation. The $F$-statistic for the Chow test for the model with volatility measure 1 had a value of 0.99412 which is not statistically significant, signifying that there is no structural break in the coefficients. The same results were obtained for the model with volatility measure 2 where the $F$-statistic for the Chow test had a value of 0.97274 .

\section{Dynamic stability}

The next step was to establish the dynamic stability of the model. When a model has AR terms, it will be dynamically stable when the roots of the AR polynomials lie strictly outside the unit circle or when the inverse roots of the AR polynomials lie strictly inside the unit circle. In our case, the plot of the inverse roots of the AR polynomial was made as shown in Figure 1. 


\section{Figure 1. Dynamic stability test}
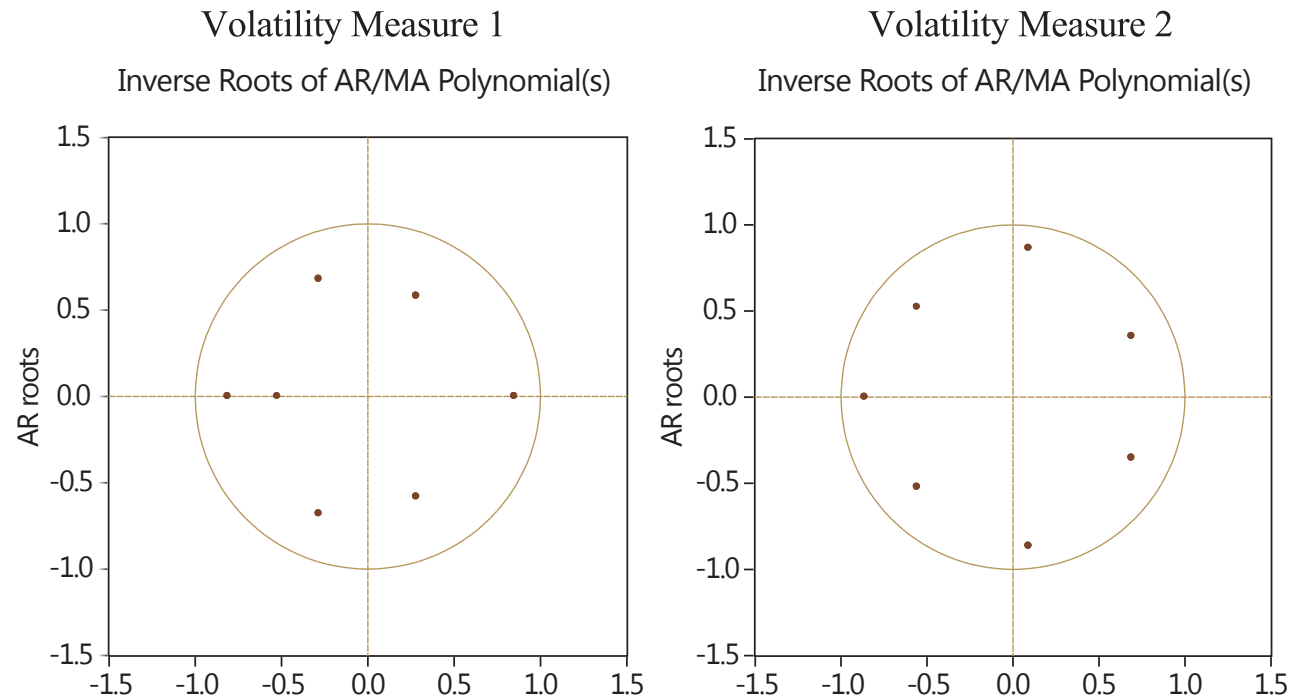

(Source) Authors' calculations.

All the inverse roots of the AR polynomials lie strictly inside the unit circle, meaning that the model is dynamically stable.

\section{Long-run relationship}

The next step was to test for the existence of long-run relationship between the dependent and the explanatory variables. The Wald bounds test, described in the fourth step above, was performed and its results are reported in Table 2. According to the computed $F$-statistic which is higher than the appropriate upper bound of the critical value shown in Table 2, the null hypothesis of no cointegration is rejected and the alternative hypothesis is adopted, concluding that there is a long run relationship between the variables. In other words, the computed $F$-statistic values using measure 1 is 10.38 and using measure 2 is 10.91 . 
Table 2. Wald bounds test for the existence of cointegration

\begin{tabular}{|c|c|c|c|}
\hline & $\begin{array}{c}\text { ARDL } \\
\text { order }\end{array}$ & $\begin{array}{c}F \text {-statistic, } \\
\text { Wald bound test }\end{array}$ & $\begin{array}{c}\text { Critical values for the } F \text {-statistic, } \\
\text { lower and upper bound } \\
\text { (from Perasan 2001) }\end{array}$ \\
\hline $\begin{array}{c}\text { Volatility } \\
\text { measure 1 }\end{array}$ & $(7,6,0,2)$ & 10.3802 & $4,066-5,119$ \\
\hline $\begin{array}{c}\text { Volatility } \\
\text { measure 2 }\end{array}$ & $(7,6,0,2)$ & 10.9142 & $4,066-5,119$ \\
\hline
\end{tabular}

(Note) All tests are performed using the $5 \%$ level of significance.

(Source) Authors' calculations.

After establishing that there is a cointegrating relationship by using the Wald test, the coefficient of the Error Correction Term (ECT) and its statistical significance was estimated and presented in Table 3. The coefficient of the ECT, $\hat{e}$, should be negative and statistically significant, meaning that there is a cointegration between the dependent and the explanatory variables. The value of this coefficient shows the percentage change of any disequilibrium between the dependent and the explanatory variables that is corrected within one period (one quarter). In our case, the sign of the ECT coefficient is, as expected, a negative value and is statistically significant. Its value ranges from -0.54 for volatility measure 1 to -0.6 for volatility measure 2 and shows that any disequilibrium between the dependent and the explanatory variables is corrected in less than a year. Note that when the value of $\hat{e}$ is larger than $|-1|$, the correction takes place in less than one quarter. In our case, a disequilibrium is corrected within two quarters. 
Table 3. Long-run impact of ERV on tourist flows

\begin{tabular}{|l|c|c|c|}
\hline & $\hat{\boldsymbol{e}}$ & $\hat{\gamma}_{i}$ & Confidence intervals for $\hat{\gamma}_{i}$ \\
\hline & & $\ln P:-0.144^{*}$ & {$[-0.227-0.061]$} \\
Volatility measure 1 & -0.543 & $\ln G D P: 11.402^{*}$ & {$[6.12516 .680]$} \\
& & $V 1:-6.304^{*}$ & {$[-12.366-0.242]$} \\
\hline & & $\ln P:-0.1736^{*}$ & {$[-0.237-0.110]$} \\
Volatility measure 2 & -0.598 & $\ln G D P: 12.401^{*}$ & {$[7.00017 .820]$} \\
& & $V 2:-7.241^{*}$ & {$[-14.326-0.156]$} \\
\hline
\end{tabular}

(Notes) $\ln P$ represents the long run value of the ratio of the relative CPIs, $\ln G D P$ represents the logarithm of a weighted index composed of the sums of each country's real GDP per-capita in PPP multiplied by the equivalent percentage of tourist arrivals of each country to Turkey, $V 1$ represents the long run value of volatility measured as a moving average and $V 2$ is the volatility capturing values above and below $6 \%$ of the average value of the moving average and $\ln P$ is the logarithm of the country's CPI to world's CPI; * indicates statistical significant coefficients at $5 \%$ level of statistical significance, the relevant confidence intervals are indicated in bold.

(Source) Authors' calculations.

Finally, the long-run impact of the explanatory variables to the dependent variable is calculated using the expression given in Equation (5). The $\widehat{\gamma}_{i}$ show how the dependent variable, the logarithm of tourist arrivals, responds in the long-run to any change in the explanatory variables i.e., the logarithm of GDP per capita of the tourists' home countries, the logarithm of relative prices, and the logarithm of the measure of exchange rate volatility. The statistical significance of the long-run coefficients is shown by the bootstrap confidence intervals as outlined by column 4 of Table 3 . The results from the examination of the effects of ERV (measures $1 \& 2$ ) on tourist arrivals indicate that ERV has a strong negative effect for Turkey for both measures of volatility, i.e., when both moving average measure is used (measure 1) and measure 2 that captures high and low fluctuation of more than $6 \%$ above and below the moving average of the exchange rate. The latter measure has a higher effect than the former (the coefficient in absolute terms is higher) indicating that high volatility affects the decisions of tourists and tour operators to a greater extent while smaller changes of the exchange rate have less effect on tourist flows.

The relative price variable is negative and significant. This finding is in line with Garin-Mynoz and Amaral (2000) and suggests that an increase in the consumer price 
index of Turkey relative to the rest of the world reduces tourist arrivals, irrespectively of what measures of volatility.

The GDP per capita variable was included because tourism services is a part of consumption which depends heavily on consumer income. The coefficient for the GDP per capita of the tourists' countries of origin was positive, statistically significant and of high value, confirming the predictions of the theory that income is an important factor in consumption of tourism services. The estimated income elasticity is very high in both models, indicating that the touristic product of Turkey is treated as a luxury good.

\section{Policy Implications}

In this study, the relationship between tourist inflows, measured by tourist arrivals, and exchange rate volatility has been examined for Turkey. Our empirical methodology relies upon the theory of cointegration, error correction representation, and different volatility measurements of the exchange rate. The results can be summarized as follows.

First, exchange rate volatility, using both measures of ERV, has indeed a significantly negative effect on tourist inflows into Turkey. By both measures, the coefficient of ERV is considerably high, around six, indicating that $1 \%$ change in the exchange rate reduces tourist flows into Turkey by more than $6 \%$. Furthermore, a comparison of ERV elasticities in the two specifications of our model shows that higher values of ERV have a larger negative impact on tourist arrivals in Turkey. Indeed, as the second specification captures high and low fluctuations (more than 6\% above and below the moving average of the exchange rate), the estimated coefficient of the ERV is larger than the one found when the ERV is measured by the moving average of the exchange rate. This result signifies that there is an escalating effect in the negative influence of the ERV on tourist flows: increased volatility reduces tourists' arrivals more than proportionately. Potential travelers, as well as tour operators, are affected more on the choice of travel destination by the extreme values of exchange rate rather than by a smooth measure.

Second, the GDP variable is GDP per capita at the origin countries, has been found to be positive and statistically significant. The values of the coefficients, representing income elasticities of tourist arrivals, are very high in the two estimated models with values more than 11 , indicating that $1 \%$ change in the per capita purchasing power at 
tourist's origin, increases the number of tourist arrivals in Turkey by more than $11 \%$. This also means that the touristic product of Turkey is treated as a luxury good.

Third, an increase in the consumer price index of Turkey relative to the rest of the world, reduces tourist arrivals irrespectively of what measures of volatility are used. This is an expected result, showing that inflation negatively affects the attractiveness of the country as a tourist destination.

We present here some possible policy implications;

- International tourist flows have increased sharply in the last six decades, becoming one of the largest and fastest growing sectors worldwide. Tourist arrivals started from 25 million in 1950 and reached 1,087 million in 2013.

- This increase in tourist arrival is expected to last, by an average long term growth of $3.3 \%$ a year, reaching 1.8 billion by 2030 (UNWTO 2011).

- This future increase in tourist arrivals will benefit emerging economies, favoring certain destinations of the world such as Europe, Asia, and the Pacific region.

- Asia and the Pacific region is expected to have the highest growth rate $(4.9 \%)$ in tourist arrivals out of all world regions.

- Financial flows associated with international tourist flows are huge and increasing, amounting to 1.4 trillion US dollars signifying a growing role of the tourist sector and justifying the reasons why governments and international institutions such as the IMF and World Bank alike, suggest that the tourist sector is a driver of economic growth and a tool for fighting the world-wide recession.

- Competition among destination countries in attracting tourists is keen and depends on a number of reasons, particularly among which prominent role is attributed to economic, political and social stability at the destination country. Instability in either economic, political or social in a country, is often, perceived by tourists in terms of an Exchange Rate Volatility (ERV) which is attributed to the economic policies followed by policymakers at the tourist destination country.

- ERV plays an important role in affecting tourist inflows into a tourist country as it leads tourists to change their holiday plans.

- The extent in which ERV negatively effects tourist inflows, however, differ among sending countries.

- Policy makers of a tourist destination country should avoid targeting tourist markets in countries exposed to either real or monetary disturbances (for instance, political instability as is the case in Ukraine, Middle East, and North Africa recently) that 
could result in an exchange rate volatility.

- A country relying heavily on its tourism industry, should avoid exercising exchange rate policies for other policy objectives, as these policies may end up to an ERV that could, substantially reduce its tourist inflows.

- Prolonged ERV escalates its negative influence on tourism flows relative to circumstantial ERV.

- Tourist product is a luxury good thus have high income elasticity, suggesting that policy makers of a destination country should target sending countries with a stable economic growth in order to ensure a stable demand for the tourist product of their country.

Received 11 August 2014, Revised 25 September 2014, Accepted 8 October 2014

\section{References}

Agiomirgianakis, George Myron and George Sfakianakis. "Short-term Microeconomic Reactions to International Crisis: The Role of Marketing Expenditure in the Profitability of Greek Tourism Enterprises.” The Empirical Economics Letters 13(2014): 887-894.

Agiomirgianakis, George Myron and George Sfakianakis. "Determinants of Tourism Demand In Greece: A Panel Data Approach.” Ekonometria Econometrics 1(2014) : 1525.

Akhtar, Masood and Spence. R. Hilton. "Effects of Exchange Rate Uncertainty on German and U.S. Trade." Federal Reserve Bank of New York, Quarterly Review 9(1984): 7-16.

Artus, Jacques R. "The Effect of Revaluation on the Foreign Travel Balance of Germany." IMF Staff Papers 17(1970): 602-17.

Awokuse, Titus O. and Yan Yuan. "The Impact Of Exchange Rate Volatility On U.S. Poultry Exports." Agribusiness 22(2006): 233-245, accessed July 23, 2014, doi: 10.1002/ agr.20082.

Bardsen, Gunnar. "Estimation of long run coefficients in error correction models." 
Oxford Bulletin of Economics and Statistics 51(1989): 345-350.

Cheng, Ka Ming. "Tourism demand in Hong Kong: income, prices, and visa restrictions." Current Issues in Tourism 15(2012): 167-181.

Chang, Chia-Lin and Michael McAleer. "Daily Tourist Arrivals, Exchange Rates and Volatility for Korea and Taiwan." Korean Economic Review 25(2009): 241-267.

Crouch Geoffrey I. "Currency Exchange Rates and the Demand for International Tourism." The Journal of Tourism Studies 4(1993): 45- 53.

De Grauwe, Paul. "Exchange Rate Variability And The Slowdown In Growth Of International Trade.” Staff Papers- International Momentary Fund 35(1988): 63-83.

Dickey, David.A. and Wayne A. Fuller. "Likelihood Ratio Statistics for Autoregressive Time Series with Unit Root." Econometrica 49(1981): 1057-1072.

Dwyer, Larry, Peter Forsyth and Wayne Dwyer. Tourism Economics and Policy. London:Channel View Publications, 2010.

Dwyer, Larry and Peter Forsyth. "Methods of estimating destination price competitiveness: a case of horses for courses?" Current Issues in Tourism 14(2011): 751-777.

Efron, Bradley and Tibshirani, Robert J., (1998), An introduction to the bootstrap, Chapman - Hall.

Fang, WenShwo, YiHao Lai and Henry Thompson. "Exchange rates, exchange risk, and Asian export revenue." International Review of Economics and Finance (2007): 237-54.

Garin-Munoz, Teresa and Teodosio Perez Amaral. "An Econometric Model for International Tourism Flows to Spain.” Applied Economics Letters 7(2000): 525-529.

Gonzalez-Gomez, Manuel, Marcos Alvarez-Diaz and Maria Seledat Otero-Giraldez. "Modeling Domestic Tourism Demand in Galicia using the ARDL approach." Tourism \& Management Studies 7(2011): 54-61.

Johansen, Soren and Katarina Juselius "Maximum Likelihood Estimation and Inference on Co-Integration - with Applications to the Demand for Money." Oxford Bulletin of Economics and Statistics 52(1990): 169-210, accessed August 10, 2014, doi:10.1111/ j.1468-0084.1990.mp52002003.x. 
Laurenceson, James and Joseph.C.H. Chai. Financial Reform and Economic Development in China. Northampton, MA:Edward Elgar, 2003.

Lee, Choonh-Ki., Turgut Var and Thomas W. Blaine. "Determinants of inbound tourist expenditures." Annals of Tourism Research 23(1996): 527-42, accessed August 10, 2014, doi: 10.1016/0160-7383(95)00073-9.

Li Gang, Haiyan Song and Stephen F. Witt. "Recent Developments in Econometric Modeling and Forecasting." Journal of Travel Research 44(2005): 82-99, accessed August 10, 2014, doi:10.1177/0047287505276594.

Oteng-Abayie, Eric Fosu and Joseph Magnus Frimpong. "Bound Testing Approach to Cointegration: An Examination of Foreign Direct Investment Trade and Growth Relationships.” Americal Journal of Applied Sciences 11(2006): 2079-2085.

Patsouratis, Vasilios, Zoe Frangouli and George Anastasopoulos. "Competition in Tourism among the Mediterranean Countries." Applied Economics 37 (2005): 18651870, accessed August 12, 2014, doi:10.1080/00036840500217226.

Pesaran, Mohammad Hashem and Bahram Pesaran. Working with Microfit 4.0: Interactive Econometric Analysis. Oxford: Oxford University Press, 1997.

Pesaran, Mohammad Hashem and Yongcheol Shin. "An Autoregressive Distributed Lag Modelling Approach to Cointegration Analysis", in Strom, S. and P. Diamond (Eds.) Econometrics and Economic Theory in the 20th Century: The Ragnar Frisch-Centennial Symposium. Cambridge: Cambridge University Press, 1999.

Pesaran, Mohammad Hashem, Yongcheol Shin and Ron Smith. "Bounds testing approaches to the analysis of level relationships." Journal of Applied Econometrics 16(2001): 289-326.

Peree, Eric and Alfred Steinherr. "Exchange Rate Uncertainty And Foreign Trade." European Economic Review 33(1989): 1241-1264, accessed September 3, 2014, doi: 10.1016/0014-2921(89)90095-0.

Phillips, Peter.C. and Pierre Perron. "Testing for a Unit Root in Time Series Regression." Biometrica 75 (1988): 335-346.

Santana, Gallego Maria, Francisco J. Ledesma-Rodríguez and Jorge V. Pérez-Rodríguez. "Exchange Rate Regimes and Tourism." Tourism Economics 16(2010): 25-43, accessed 
September 4, 2014, doi: 10.5367/ 000000010790872015.

Serenis, Dimitrios and Nicholas Tsounis. "Exchange Rate Volatility and Aggregate Exports: Evidence from two Small Countries." ISRN Economics (2014): 1-10, accessed 19/10/2014, doi:10.1155/2014/839380.

Serenis, Dimitrios and Nicholas Tsounis. "The Effects of Exchange Rate Volatility on Sectoral Exports. Evidence from Sweden, the U.K. and Germany." International Journal of Computational Economics and Econometrics (2014), (in print).

Song, Haiyan and Gang Li. "Tourism Demand Modeling and Forecasting-A review of Recent Research.” Tourism Management 29(2008): 203-220, accessed September 15, 2014, doi: 10.1016/j.tourman.2007.07.016.

Stabler, Mike J., Andreas Papatheodorou and Thea M. Sinclair. The Economics of Tourism. $2^{\text {nd }}$ ed. Routledge, 2010.

Thompson, Alexi and Henri Thompson. "The exchange rate, euro switch, and tourism revenue in Greece." Tourism Economics 16(2010): 773-780, accessed Septmber 15, 2014, doi:10.5367/000000010792278338.

Tremblay, Pascal. "Polling International Tourism in Western Europe." Annals of Tourism Research 16(1989): 479-91.

Webber, Anthony G. "Exchange Rate Volatility and Cointegration in Tousim Demand." Journal of travel Research 39(2001): 398-405, accessed September 16, 2014, doi: 10.1177/004728750103900406.

Witt, Stephen F. and Christine A. Martin. "International Tourism Demand Modelsinclusion of Marketing Variables." Tourism Management 8(1987): 33-40, accessed September 17, 2014, doi: 10.1016/0261-5177(87)90037-9.

Witt, Stephen F. and Christine A. Witt. "Forecasting Tourism Demand: A Review of Empirical Research." International Journal of Forecasting 11(1995): 447-475, accessed September 20, 2014, doi: 10.1016/0169-2070(95)00591-7.

Yap, Ghialy Choy Lee. "An Examination of the Effects of Exchange Rates on Australia's Inbound Tourism Growth: A Multivariate Conditional Volatility Approach." International Journal of Business Studies 20(2012): 111-32.

Zaki, Ahmed. “An Econometric Model Forecasting Egypt's Aggregate International 
Tourism Demand and Revenues." Tourism and Hospitality Planning \& Development 5(2008): 215-232.

Zhang Yujuan, Hailin Qu and Pimtong Tavitiyaman. "The Determinants of the Travel Demand on International Tourist Arrivals to Thailand." Asia Pacific Journal of Tourism Research 14(2009): 77-92, accessed August 11, 2014, doi: 10.1080/ 10941660902728080.

United Nations World Tourism Organisation. Tourism Highlights. New York:UNWTO, 2014.

United Nations World Tourism Organisation. Tourism towards 2030 Global Overview. New York:UNWTO, 2011. 


\section{Appendix: ARDL regression results}

Dependent variable: $\Delta \mathrm{X}_{\mathrm{t}}$

\begin{tabular}{|c|c|c|}
\hline & ARDL order & Regressor, coefficient \\
\hline $\begin{array}{l}\text { Volatility measure } 1 \\
\text { F-statistic, LM test: } 1.108874 \\
\text { Dynamic stability: yes } \\
\text { Heteroskedasticity Test, } F \text {-statistic: } 0.736037\end{array}$ & $(7,6,0,2)$ & 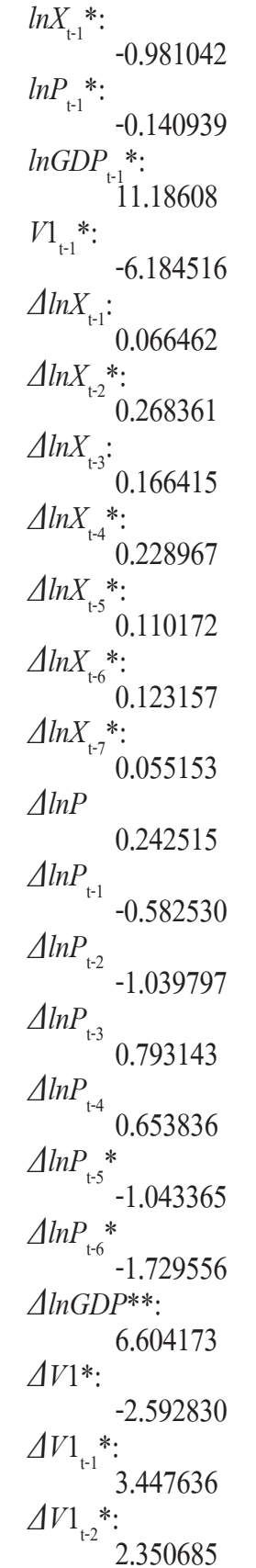 \\
\hline
\end{tabular}


(continued)

\begin{tabular}{|c|c|c|}
\hline & ARDL order & Regressor, coefficient \\
\hline $\begin{array}{l}\text { Volatility measure } 2 \\
F \text {-statistic, LM test: } 0.5347 \\
\text { Dynamic stability: yes } \\
\text { Heteroskedasticity Test, } F \text {-statistic: } 1.447288\end{array}$ & $(7,6,0,2)$ & 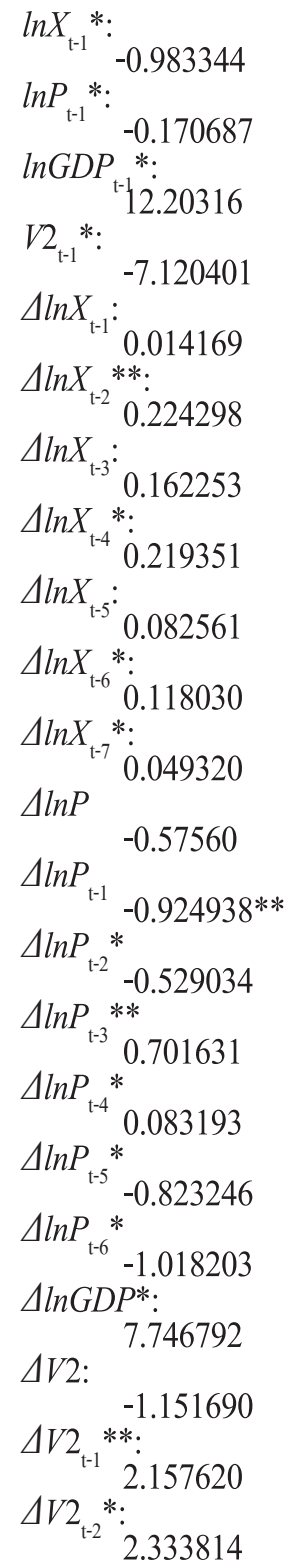 \\
\hline
\end{tabular}

(Notes) $X$ represents the number of tourist arrivals, $P$ represents the ratio of the relative CPIs, $\ln G D P$ represents the logarithm of a weighted index composed of the sums of each countries real GDP per-capita in PPP multiplied by the equivalent percentage of tourist arrivals of each country to Turkey. $V 1$ represents volatility measured as a moving average and $V 2$ is volatility depicting values above and below $6 \%$ of the average value of the moving average. $V 1, V 2$ is in logarithmic form. * denotes up to $5 \%$ and ** denotes up to $10 \%$ level of statistical significance. The plot of the inverse roots of the AR polynomials for examining the dynamic stability of the model are presented in Figure 1.

(Source) Authors' calculations. 